\title{
Performance and Design of an L-C-L Converter for Voltage Regulator Type Applications
}

\author{
Chandan Chakraborty, student member, Muneaki Ishida, member and Takamasa Hori, member, \\ Mie University, Mie 514-8507, Japan
}

In resonant converters, lagging power factor operation is preferred. Also, if the converter switches are operated at constant frequency, or during the operating load range, the change in frequency is kept minimum, then the switch as well as the converter components can be best utilized. The paper investigates a three-element L-C-L converter topology to operate with minimum change in operating frequency. The analysis and performance are reported for lagging power factor mode of operation. The analysis yields easy-to-use closed-form equations, which can be used to design the converter. Design criteria for voltage regulator type applications are discussed. The usefulness of the design methodology is proved by prototype experiments.

Keywords: Resonant converter, High-frequency, Voltage regulator, Converter design

\section{Introduction:}

Resonant converters[1-17] are smaller in size and because of ZVS and/or ZCS operation, the switching losses are drastically reduced. Additional snubber components and heat sink are no longer required. Also selection of operating frequency beyond audible range enables noisefree operation.

The two most popular topology for DC/DC converters are Series Resonant Series Loaded (normally called as Series Resonant Converter or SRC) and Series Resonant Parallel Loaded (normally called as Parallel Resonant Converter or PRC) [1-3]. The part-load efficiency of the SRC is good but the no-load regulation is the poorest. In fact the no load voltage cannot be regulated by frequency regulation. This makes SRC unsuitable for voltage regulator type applications, when controlled by frequency adjustment. On the other hand PRC provides excellent regulation at no-load, thus became a strong candidate for voltage regulator type applications[7].

The PRC has the advantage of minimum components count but the major problem is that of poor part-load efficiency. Efforts to improve upon the basic PRC structure unearthed different multi elements SeriesParallel topologies[3,7-10,13-17]. Extensive investigations have been conducted on this topologies but interestingly in many cases efforts towards providing guide line for better design in specific applications are missing in literature. The present paper deals with the L-C-L topology[8] for voltage regulator applications. The topology is explained first followed by design criteria, converter analysis, design, performance and results from experiments.

\section{Converter Description:}

Fig.1 shows the topology considered for the present study. The load is connected across $\mathrm{C}_{1}$ in series with $\mathrm{L}_{2}$. Thus the converter preserves the basic parallel structure and at no-load behaves exactly in the same way. Although the converter in its present form was reported earlier [8], but different aspects of better design for voltage regulator type applications are missing, which is pursued in the present paper. It has been shown later in this report

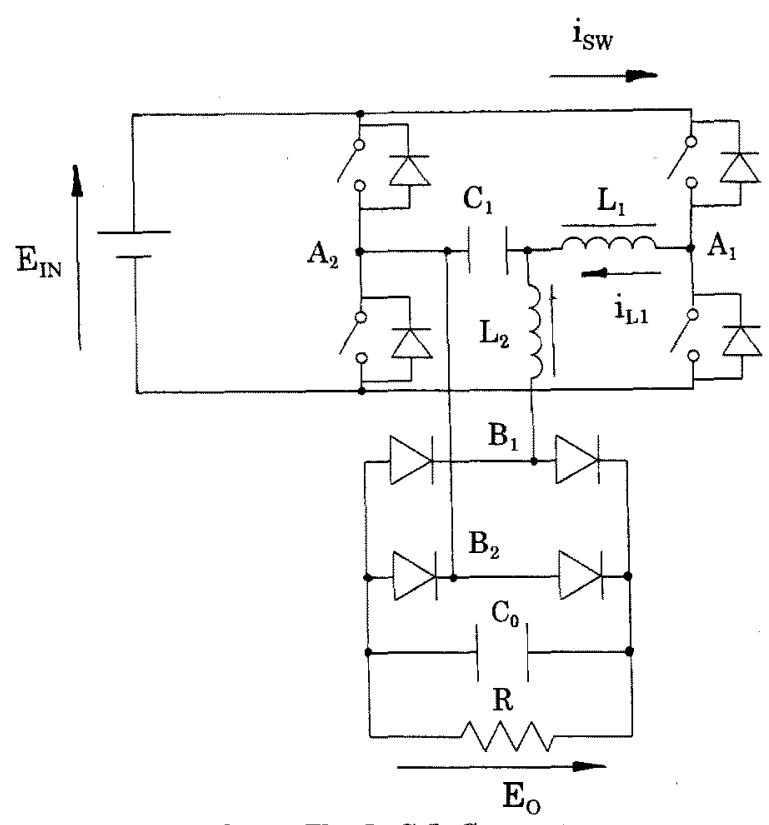

Fig. 1. The L-C-L Converter.

that a proper selection of $L_{2}$ provides load-independent characteristics. Although L-C.C converter is topologically more attractive for it requires only one inductor, which is bigger in size compared to a capacitor, however, this should not be a basic guideline for the selection of converter topology, because capacitor in series with the load should be able to carry higher current and inductor size reduces with the selection of higher operating frequency. Although full bridge inverter at the input and normal diode bridge at the output are used but, depending on application requirement, half-bridge or totem pole inverter may be used. Also use of transformer at the output side of the L-C$L$ resonant circuit provides option for use of half-wave rectifier or bridge rectifier. Fig. 2 shows several options for transformer coupled converters. The winding leakage 


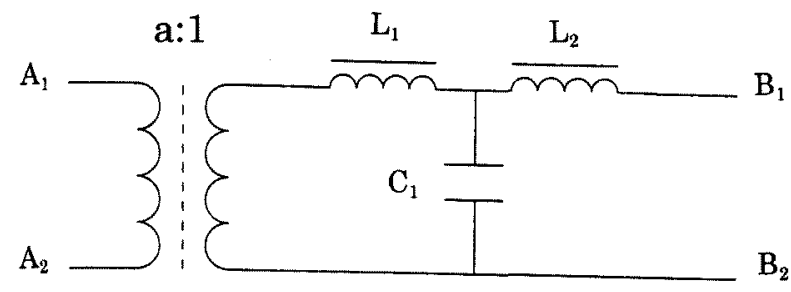

(a)

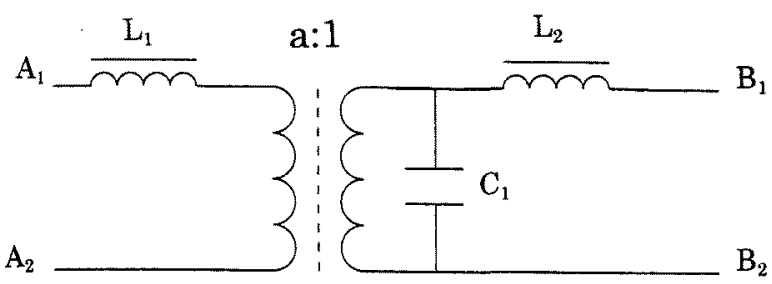

(b)

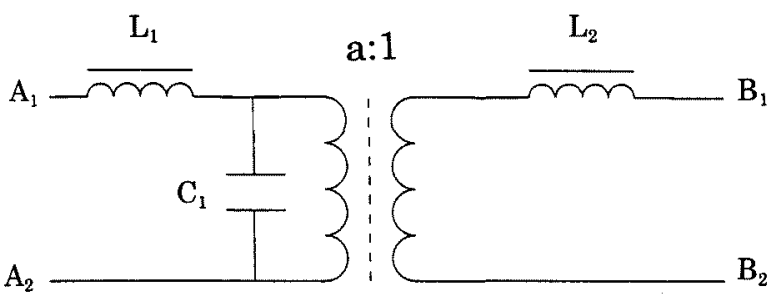

(c)

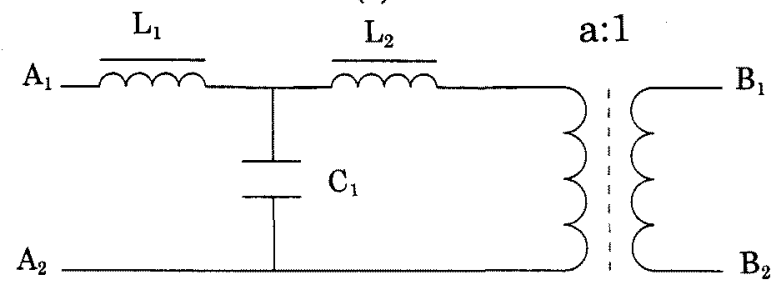

(d)

Fig.2. Transformer Coupled L-C-L Topologies.

inductance may be properly designed to replace one of the inductors in each of the cases.

\section{Design Griteria:}

A design should be judged or evaluated on the basis of the selected criteria. Converter design depends on specific application, control methodology and on the type of the converter itself. For the resonant converters, it has been well explained that operation above resonance (i.e. at operating frequency greater than resonating frequency) eliminates snubber requirements[7] and thus now-a-days have become a standard choice for many applications. Also, minimum deviation in operating frequency to control the converter output voltage ensures better utilization of the switches and converter components[11-12,14]. The third aspect is design for better part-load efficiency. So the present study on voltage regulator type applications is based on the following criteria,

(i) Operation in above resonance or lagging power factor mode

(ii) Operation at constant frequency or under minimum variation in frequency,

(iii)Better part-load efficiency.

\section{Converter Analysis:}

The fundamental frequency approach is followed to yield closed-form equations and to facilitate converter design. The different symbols used in this paper are explained below. Only $\mathrm{E}_{\mathrm{IN}}$ and $\mathrm{E}_{\mathrm{O}}$ are $\mathrm{DC}$, all other symbols for voltages and currents expressed in uppercase letters, indicate $\mathrm{AC}$ rms quantities.

$E_{I N}=$ Input DC Voltage,

$E_{o}=$ Output DC Voltage,

$V_{I N}=$ Rms magnitude of the fundamental component of the inverter output voltage,

$V_{O}=$ Rms magnitude of the fundamental component of the voltage at the input of the rectifier bridge,

Converter AC Voltage Gain (M) may be defined as,

$$
M=\frac{V_{O}}{V_{I N}}
$$

$M_{N L}=$ Converter AC voltage gain at no-load,

$I_{N L}=$ Current through $\mathrm{L}_{1}$ and $\mathrm{C}_{1}$ at no-load (No-load current),

$I_{F L}=$ Current through $\mathrm{L}_{2}$ at rated load,

$R$ = Load resistance,

$R_{F L}=$ Rated load resistance,

$P_{\text {O(FL) }}=$ Rated power output,

$R_{a c}=$ Reflected equivalent resistance on the $\mathrm{AC}$ side,

$a=$ Transformer turns ratio

$V_{T H}=$ Thevenin Voltage,

$Z_{T H}=$ Thevenin impedance,

$\omega_{0}=\frac{1}{\sqrt{L_{1} C_{1}}}$

$Q_{1}=\frac{r}{\omega_{0} L_{1}}$

$\alpha=1-\left(\frac{\omega_{0}}{\omega}\right)^{2}$

$\beta=\frac{I_{N L}}{I_{F L}}$

$\gamma=\frac{L_{2}}{L_{1}}$

$C_{2}^{\prime}=\alpha C_{1}$

$Q_{2}=\frac{\omega_{0} L_{1}}{R}$

denom $=\sqrt{\left[\left(\frac{\omega}{\omega_{0}}\right)^{2} Q_{1}^{2}+\left\{\left(\frac{\omega}{\omega_{0}}\right)^{2}-1\right\}^{2}\right]}$

The inverter converts the input DC voltage $\left(E_{I N}\right)$ to a square wave voltage $(v)$ expressed as,

$$
\begin{aligned}
v= & E_{\mathrm{IN}} \quad \text { for } 0<\omega \mathrm{t} \leq \pi \\
-E_{\mathrm{IN}} & \text { for } \pi<\omega \mathrm{t} \leq 2 \pi
\end{aligned}
$$


Fig.3 shows the equivalent AC network, where $r$ represents the sum of switch on-resistance, the resistance of the inductor $L_{1}$ and source resistance (if any). $V_{I N}, \mathrm{R}_{\mathrm{ac}}$ and $V_{O}$ may be expressed as below,

$$
\begin{gathered}
V_{I N}=\frac{2 \sqrt{2}}{\pi}\left(E_{I N}-2 V_{S W} \ldots\right) \\
R_{a c}=\left(\frac{8}{\pi^{2}}\right)
\end{gathered}
$$

$V_{o}=\frac{2 \sqrt{2}}{\pi}\left(E_{o}+2 V_{d}\right)$

Where $V_{S W}$ and $V_{d}$ are the on-state voltage drop in inverter switch and forward voltage drop in diode respectively.

Thus Converter AC Voltage Gain may be expressed as,

$$
M=\frac{V_{O}}{V_{I N}}=\frac{E_{o}+2 V_{d}}{E_{I N}-2 V_{S W}}
$$

It is evident from (5) that the Converter DC Voltage Gain (i.e. $\mathrm{E}_{\mathrm{O}} / \mathrm{E}_{\mathrm{IN}}$ ) will be same to that of Converter AC Voltage Gain if the drops in inverter switches and output diodes are neglected. However, knowing the switch and diode drops, Converter DC Voltage Gain can easily be calculated from (5).

Fig.4 shows the Thevenin's equivalent circuit of Fig.3, where $V_{\mathrm{TH}}$ and $\mathrm{Z}_{\mathrm{TH}}$ are expressed as

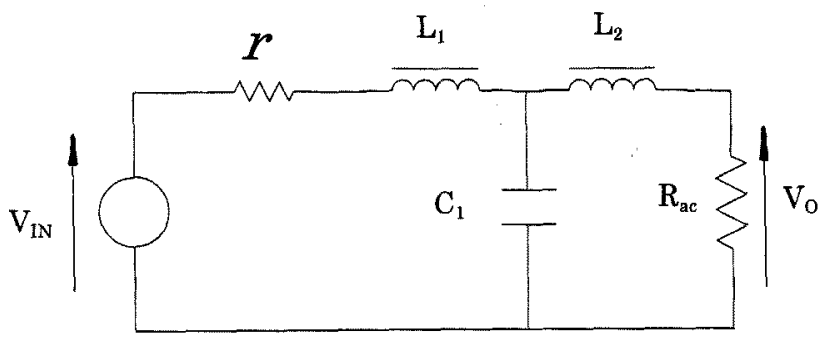

Fig.3. Equivalent AC Network.

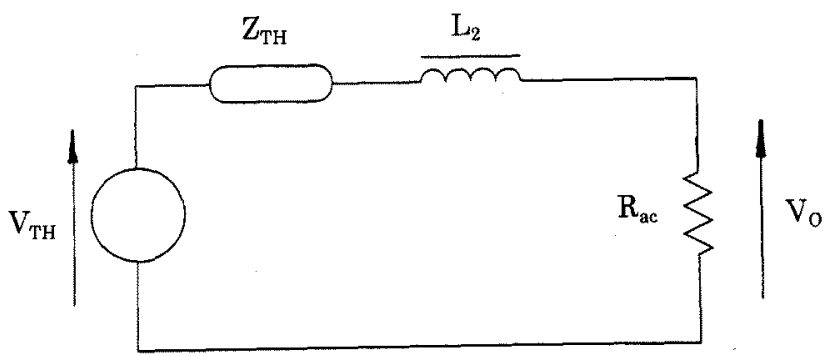

Fig.4. Thevenin`s Equivalent Circuit.

$$
V_{T H}=\frac{V_{I N}}{\text { denom }}
$$

$Z_{T H}=R_{T H}+j X_{T H}$

Where

$$
R_{T H}=\frac{r}{(\text { denom })^{2}}
$$

$X_{r H}=\frac{-\omega L_{1}\left[\left\{\left(\frac{\omega}{\omega_{0}}\right)^{2}-1\right\}+Q_{1}^{2}\right]}{(\text { denom })^{2}}$

As $r \ll \omega \mathrm{L}_{1}$, so neglecting $r$ and $\mathrm{Q}_{1}$, equations 6,8 and 9 take the following form,

$$
\begin{aligned}
& V_{T H}=\frac{V_{I N}}{\left[\left(\frac{\omega}{\omega_{0}}\right)^{2}-1\right]} \\
& R_{T H}=0 \text {. }
\end{aligned}
$$

For $\omega>\omega_{0}, X_{T H}$ is negative thus may also be expressed in terms of capacitance as shown below

$$
X_{T H}=\frac{-1}{\left[1-\left(\frac{\omega_{0}}{\omega}\right)^{2}\right] \omega C_{1}}=\frac{-1}{\omega C_{2}}
$$

Thus the operation above resonance created a capacitance in series with the load. Taking into account that $\mathrm{V}_{\mathrm{TH}}=\mathrm{V}_{\mathrm{ML}}$ the simplified equivalent circuit is shown in Fig.5.

From (10), the no-load gain may be expressed as

$$
M_{N L}=\frac{1}{\left[\left(\frac{\omega}{\omega_{0}}\right)^{2}-1\right]}
$$

The no-load current (flowing through $\mathrm{L}_{1}$ and $\mathrm{C}_{1}$ when load current is zero) may be expressed as,

$$
I_{N L}=\frac{V_{I N}}{\omega_{0} L_{1} \sqrt{\left[Q_{1}^{2}+\left(\frac{\omega}{\omega_{0}}-\frac{\omega_{0}}{\omega}\right)^{2}\right]}}
$$

Neglecting $\mathrm{Q}_{1}$, the expression of $\mathrm{L}_{1}$ becomes,

$$
L_{1}=\frac{V_{I N}}{\omega_{0} \beta I_{F L}\left(\frac{\omega}{\omega_{0}}-\frac{\omega_{0}}{\omega}\right)}
$$




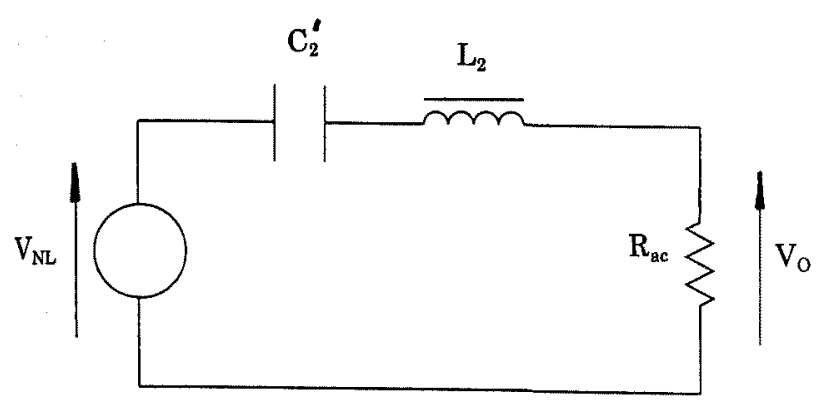

Fig.5. Simplified AC Network.

Also in terms of $M, L_{1}$ is,

$$
L_{1}=\frac{8 R_{F L}}{\omega_{0} \beta M \pi^{2}\left(\frac{\omega}{\omega_{0}}-\frac{\omega_{0}}{\omega}\right)}
$$

The AC voltage gain may be expressed as

$$
M=\frac{1}{(\text { denom }) \sqrt{\left[1+\frac{\pi^{4}}{64} Q_{2}^{2}\left\{\gamma\left(\frac{\omega}{\omega_{0}}\right)-\frac{1}{\alpha}\left(\frac{\omega_{0}}{\omega}\right)\right\}^{2}\right]}}
$$

Again neglecting $Q_{1}$, the equation simplifies to,

$$
M=\frac{1}{\left[\left(\frac{\omega}{\omega_{0}}\right)^{2}-1\right] \sqrt{\left[1+\frac{\pi^{4}}{64} Q_{2}^{2}\left\{\gamma\left(\frac{\omega}{\omega_{0}}\right)-\frac{1}{\alpha}\left(\frac{\omega_{0}}{\omega}\right)\right\}^{2}\right]}}
$$

Thus $M$ will become independent of load variation if

$$
\frac{\pi^{4}}{64} Q_{2}^{2}\left\{\gamma\left(\frac{\omega}{\omega_{0}}\right)-\frac{1}{\alpha}\left(\frac{\omega_{0}}{\omega}\right)\right\}^{2}=0
$$

Simplification of (19) results in

$$
\gamma=\frac{L_{2}}{L_{1}}=\frac{1}{\left[\left(\frac{\omega}{\omega_{0}}\right)^{2}-1\right]}
$$

The currents through the converter elements $L_{1}, C_{1}$ and $L_{2}$ may be expressed as,

$$
I_{L 1}=V_{o} \omega C_{1} \sqrt{1+\frac{\pi^{4}}{64} Q_{2}^{2}\left\{\gamma\left(\frac{\omega}{\omega_{0}}\right)-\left(\frac{\omega_{0}}{\omega}\right)\right\}^{2}}
$$

$$
I_{C 1}=V_{o} \omega C_{1} \sqrt{1+\frac{\pi^{4}}{64} \gamma^{2} Q_{2}^{2}\left(\frac{\omega}{\omega_{0}}\right)^{2}}
$$

$$
I_{L 2}=\frac{\pi^{2}}{8} V_{o} \frac{Q_{2}}{\omega_{0} L_{1}}
$$

The voltages across the different elements may be expressed as,

$$
\frac{V_{L 1}}{V_{I N}}=M\left(\frac{\omega}{\omega_{0}}\right)^{2} \sqrt{1+\frac{\pi^{4}}{64} Q_{2}^{2}\left\{\gamma\left(\frac{\omega}{\omega_{0}}\right)-\left(\frac{\omega_{0}}{\omega}\right)\right\}^{2}}
$$

$$
\frac{V_{C 1}}{V_{I N}}=M \sqrt{1+\frac{\pi^{4}}{64} \gamma^{2} Q_{2}^{2}\left(\frac{\omega}{\omega_{0}}\right)^{2}}
$$

$$
\frac{V_{L 2}}{V_{I N}}=\frac{\pi^{2}}{8} \gamma M Q_{2}\left(\frac{\omega}{\omega_{0}}\right)
$$

The expression of the total inductance is

$$
L_{T}=L_{1}+L_{2}=L_{1}(1+\gamma) \text {. }
$$

In terms of $M$, equation 27 may be expressed as,

$$
L_{T}=\frac{8 R_{F L}(1+M)^{2}}{\pi^{2} \omega \beta M}
$$

Thus for a chosen operating frequency and $\beta, L_{T}$ becomes minimum when

$$
\frac{d L_{T}}{d M}=0
$$

which yields the value of $\mathrm{M}$ to be 1 . The corresponding $\omega / \omega_{0}$ is $\sqrt{2}$. The total minimum inductance which occurs when $\mathrm{M}=1$ (with corresponding $\gamma=1$ ), may be expressed as,

$$
L_{T(M I N)}=\frac{32 R_{F L}}{\omega \beta \pi^{2}}
$$

As the currents through $L_{1}$ and $L_{2}$ are different, so minimum total inductance magnitude does not necessarily yield minimum size. It is well known that the inductor size is proportional to its energy storage capacity. Thus for a specific core material and for a desired temperature rise and insulation type, the combined size of the inductor is minimum when

$$
\frac{d}{d M} \frac{1}{2}\left(L_{1} I_{L 1}^{2}+L_{2} I_{L 2}^{2}\right)=0
$$


Which when simplified becomes,

$2 M^{3}+2 M^{2}-\beta^{2}=0$

Thus for a desired $\beta, M$ (and also corresponding $\gamma$ ) can be found from (32) to make the total inductor size minimum.

In practice input and output voltage being specified, the designer has no chance to manipulate $M$, however for transformer isolated converters, adjusting transformer turns ratio, a better design may be achieved. This aspect is discussed briefly, later in section 6.2 .

\section{Performance Gharacteristics:}

For a voltage regulator, from load point of view, the extreme conditions are no-load and short-circuit. A PRC structure is topologically short-circuit proof. But the addition of $\mathrm{L}_{2}$ in the PRC structure (resulting in L-C-L topology), introduces series characteristics and when $\gamma$ is selected according to (20), the converter operates at resonance and loses the inherent short-circuit protection feature. However this is not a big problem, because, the short-circuit protection can easily be included in the control circuitry, which when short-circuit occurs, makes the frequency much higher, thus operating safely away from the resonant point.

To study the performance of the converter, different curves are plotted in a systematic manner. Fig.6 shows the variation of $A C$ voltage gain at no-load with the change in frequency ratio. Depending on the output voltage, the frequency ratio may be selected from this curve. At no-load condition as $\mathrm{L}_{2}$ has no part to play, so the L-C-L converter and the PRC behave identically at no-load. Fig.7 and 8 show the converter $\mathrm{AC}$ voltage gain vs. frequency ratio characteristics at different values of $\gamma$, for two different loads, corresponding to $Q_{2}=5$ and 1 respectively. It is obvious that with lower $Q_{2}$, the $M$ vs. $\omega / \omega_{0}$ curve will approach the no-load characteristics. However due to the presence of $L_{2}$, there is a marked difference in the load characteristics compared to the normal PRC, which is clearly reflected in Fig.8. Instead of actual magnitude, $\mathrm{L}_{2}$ is taken into account by the ratio $\gamma$, to facilitate design and for a better understanding of the network. For a definite load, increase in the magnitude of

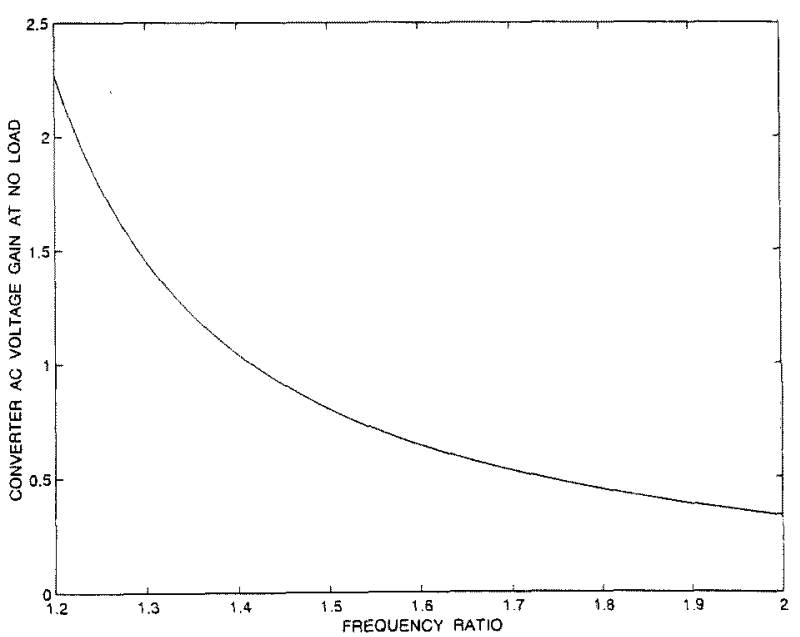

Fig. $6 . \mathrm{M}_{\mathrm{NL}}$ vs. $\omega / \omega_{0}$

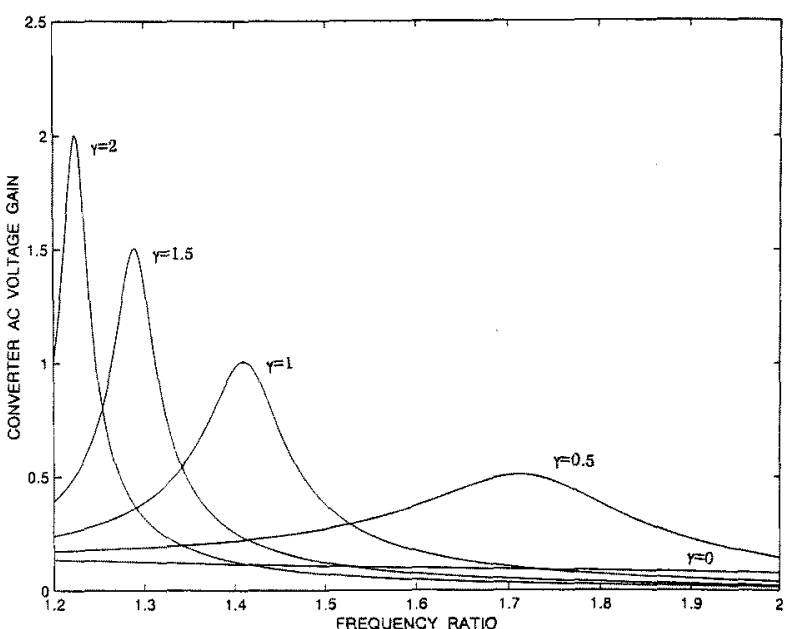

Fig.7. $M$ vs. $\omega / \omega_{0}$ for $Q_{2}=5$.

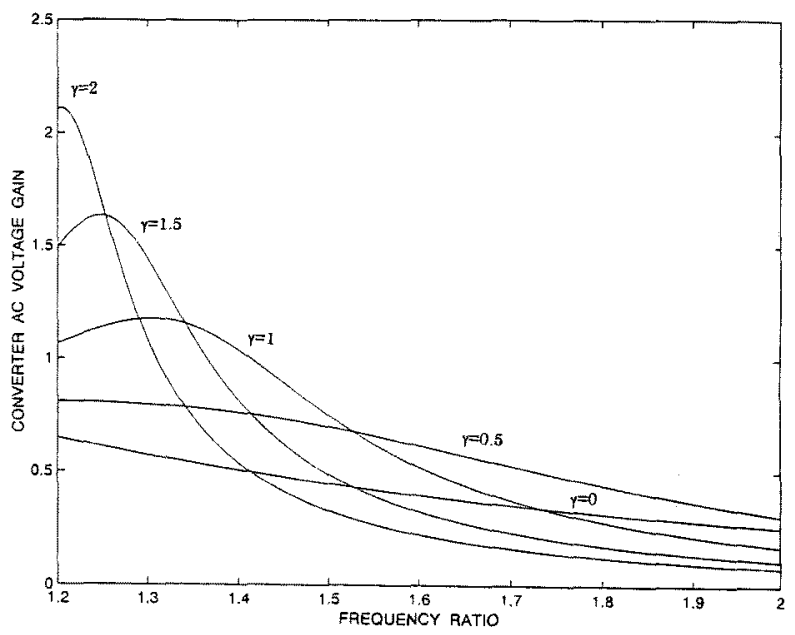

Fig.8. M vs. $\omega / \omega_{0}$ for $Q_{2}=1$.

$\gamma$, moves the resonance peak towards lower magnitude of the $\omega / \omega_{0}$. Also a comparison of Fig. 7 and 8 reflects that increase in $Q_{2}$ (or load) also makes the $M$ vs. $\omega / \omega_{0}$ characteristics more sharp (frequency sensitive). In Figs. 7 and 8, the case for $\gamma=0$ is also included for comparison with the PRC. Selection of $\gamma$ and operating frequency is very important for a better performance of the converter.

Fig.9 shows the converter $\mathrm{AC}$ voltage gain vs. $\omega / \omega_{0}$ characteristics for different loads at a specific $\gamma$. The frequency of operation at which load independency occurs, is shown in Fig.9 as the point "A". From Fig.9 it is clear that at higher loads, operating frequency higher than $\omega_{A}$, ensures lagging power factor operation, and if the frequency becomes less than $\omega_{A}$, then depending on the magnitude of the load, the converter may enter in the leading power factor mode. Fig.10 shows the load characteristics (i.e. $M$ vs. $Q_{2}$ ) for different values of $\gamma$. As the converter gain is considered to be 1 , so when $\gamma=1$ (i.e. $M=\gamma$ ), the characteristic shows load independent feature. At all other values of $\gamma$ the converter output voltage undergoes regulation. 


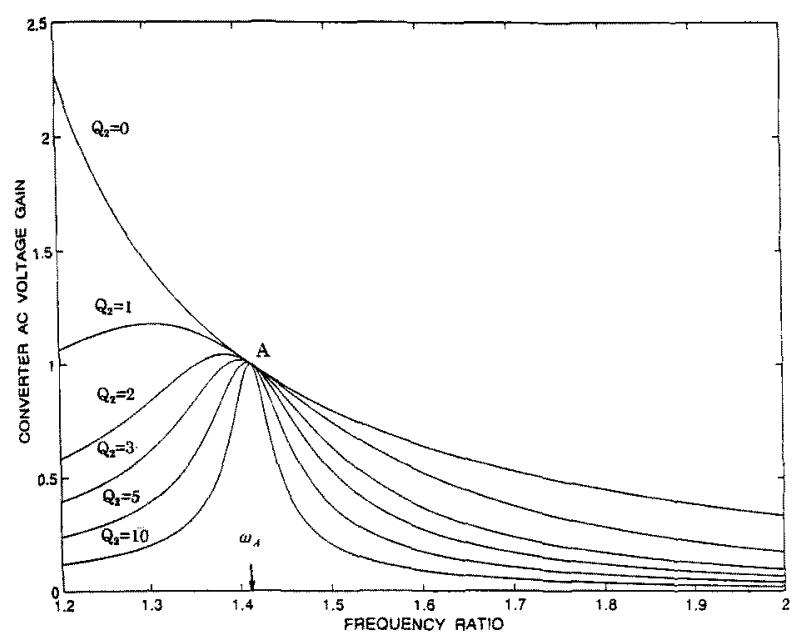

Fig.9. M vs. $\omega / \omega_{0}$ for $\gamma=1$.

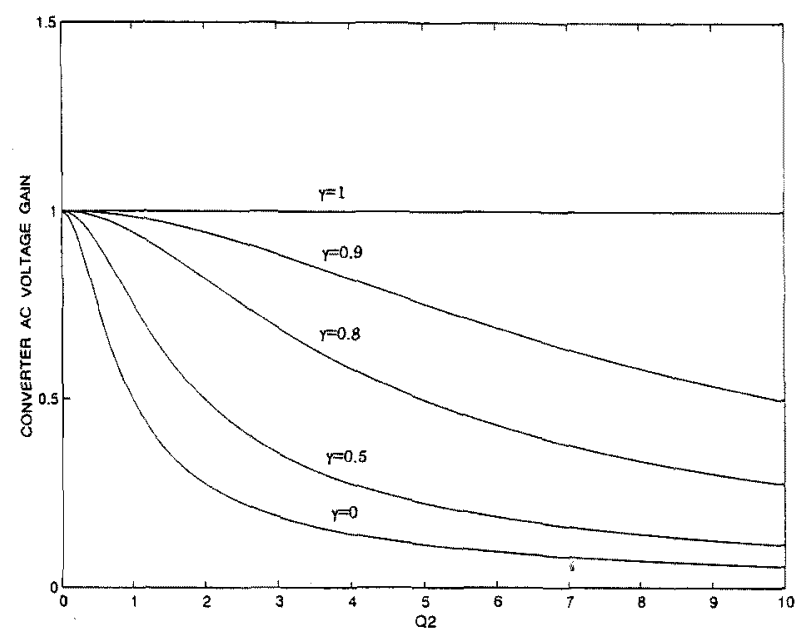

Fig.10. $M$ vs. $Q_{2}$ at $\omega \sqrt{ } \omega_{0}=\sqrt{ } 2$.

For a series resonant type converter (SRC), efficiency becomes best if the converter is operated at resonance (i.e. at resonating frequency). Because at resonance the reactive component of the current is minimum (zero), thus for the same power transfer conduction loss is minimized. A PRC can never be operated at resonance (i.e. at resonating frequency) [7], whereas the L-C-L converter with a proper selection of operating frequency and $\gamma$, may be operated at resonance corresponding to load higher than the no-load. if the noload current is restricted to a lower magnitude, the partload efficiency of such converter will be definitely better compared to a PRC. Efficiency computations need device and components details and hence not pursued here. However, it can easily be calculated by computing the currents $I_{L 1}, I_{C 1}$ and $I_{L 2}$ using (21), (22) and (23) respectively and then the losses associated with the converter components and devices.

\section{Bonverter Design:}

Converter design involves determination of the device voltage/current ratings, selection of components magnitude and operating frequency along with the details of the control circuitry. However this paper deals only with the selection of components (i.e. $L_{1}, C_{1}$ and $L_{2}$ ) magnitude for better performance. The rest of the design will follow standard procedure [3].

If there is no input voltage variation, the converter may be designed optimally to operate at constant frequency by selecting a proper $\gamma$. But voltage regulator type applications demand constant output voltage under the circumstances of input voltage and output load variation (within specified range). So operating frequency and $\gamma$ should be selected corresponding to the highest $M$ (i.e. for the case of lowest possible input voltage). For lower $M$ (i.e. lower than the "highest $M$ " for which the converter is designed), output voltage may be controlled by controlling (slightly increasing) the frequency.

\subsection{Design for transformer-less converter:}

The combination $L_{1}, C_{1}$ and $\omega$ decides $I_{N L}$ and the output voltage at no-load. $\mathrm{L}_{2}$ decides the load performance and if $\gamma=M$, then the converter exhibits load independent features. $R_{F L}$ may be calculated as

$$
R_{F L}=\frac{E_{O}^{2}}{P_{O(F L)}}
$$

If the converter is supposed to deliver power, more than the rated (may be for short interval), then, $R_{\mathrm{FL}}$ should be calculated considering the specified maximum power output from the converter, and if by any chance during operation the converter power exceeds the specified maximum value, then the base/gate drive to the converter devices must be withdrawn to avoid entering into the leading power factor mode.

For a specified $E_{0}$ and $E_{I N}, M$ may be computed using (5). If input voltage undergoes variation, $M$ should be calculated corresponding to the minimum $\mathrm{E}_{\mathrm{IN}}$. Assuming $\beta$ and operating frequency (i.e. $\omega$ ), $\mathrm{L}_{1}$ may be calculated using the following equation (derived from (16)),

$L_{1}=\frac{8 R_{F L}(1+M)}{\pi^{2} \omega \beta M}$

$\mathrm{C}_{1}$ may be calculated from the following equation,

$C_{1}=\frac{1+M}{\omega^{2} M L_{1}}$

$\mathrm{L}_{2}$ may be calculated using (20).

Thus it is understood that the designer has to select $\beta$ and $\omega$. As higher $\omega$ allows miniaturization of the network components, so operating frequency selection is decided by the upper allowable working frequency limit of the converter devices. A lower $\beta$ yields better part-load efficiency but demands increased inductance magnitude, thus increasing the size of the converter. So a trade-off is necessary in between converter allowable size (with the associated increase in cost) and efficiency.

The converter components of an IGBT based 48 volts $( \pm 10 \%)$ input, 24 volts output (i.e. Bulk Type), transformer less converter for a maximum load current of $5 \mathrm{~A}$ are calculated as below. Operating frequency has been selected to be $30 \mathrm{kHz}$. The IGBT drop and diode drop are considered to be 2.5 Volts and 2 volts respectively For $\beta=0.1 \mathrm{~L}_{1}=488 \mu \mathrm{H}, \mathrm{C}_{1}=0.136 \mu \mathrm{F}, \mathrm{L}_{2}=357.6 \mu \mathrm{H}$, For $\beta=0.5 \mathrm{~L}_{1}=97.6 \mu \mathrm{H}, \mathrm{C}_{1}=0.68 \mu \mathrm{F} \mathrm{L}=71.5 \mu \mathrm{H}$. 
The converter components of a 24 volts $( \pm 10 \%)$ input and 48 volts output (i.e. Boost Type), $2.5 \mathrm{~A}$, for the same operating frequency are calculated as follow

For $\beta=0.1, \mathrm{~L}_{1}=1.315 \mathrm{mH}, \mathrm{C}_{1}=34 \mathrm{nF}, \mathrm{L}_{2}=2.21 \mathrm{mH}$,

For $\beta=0.5, L_{1}=263 \mu \mathrm{H}, \mathrm{C}_{1}=0.17 \mu \mathrm{F}, \mathrm{L}_{2}=443.6 \mu \mathrm{H}$.

\subsection{Design for transformer-isolated converter:}

In case of transformer-isolated converters, the designer has a little more flexibility. The transformer turns ratio may be properly designed to have control over the ratio $\omega \omega_{0}$. However, transformer non-linearities will also have a part to play in the converter performance, which needs further investigations. Assuming ideal transformer and considering the circuit topology of Fig.2a, equation 32 takes the following form

$$
2(a M)^{3}+2(a M)^{2}-\beta^{2}=0
$$

So, to design a converter with minimum inductor size "aM" can be found from (36), assuming $\beta$. Thus $E_{\mathrm{NN}}$ and $E_{0}$ being specified, the turns ratio "a", can easily be calculated. Fig.11 shows a plot of (36) (only the real positive root of "aM" vs. $\beta$ ), which shows a lower $\beta$ requires lower "aM".

It is sufficient to design the transformer considering only the active power equal to the rated output power of the converter. This is because with proper design, the output AC current of the inverter at rated load, will become in phase with the inverter output voltage. Thus neglecting the effect of the magnetizing current of the transformer, the transformer voltages and currents become in phase at rated load. So in the present case, optimization of the combined inductors size will lead to a total sizeoptimization of the transformer-isolated converter.

It is mentioned earlier that with proper design and no input voltage variation, the required variation of operating frequency with the change in load is minimum (ideally zero). However for voltage regulator applications, usually the input voltage also changes. As for lower magnitude of $\gamma$, the $M$ vs. $\omega / \omega_{0}$ characteristic becomes more flat, so, the required variation in operating frequency with the change in input voltage increases with decrease in $\gamma$. Thus a careful selection of " $a$ " and $\gamma(=a M)$ are required for better performance. Also, a compromise between converter size and performance may be essential in case of lower $\gamma$.

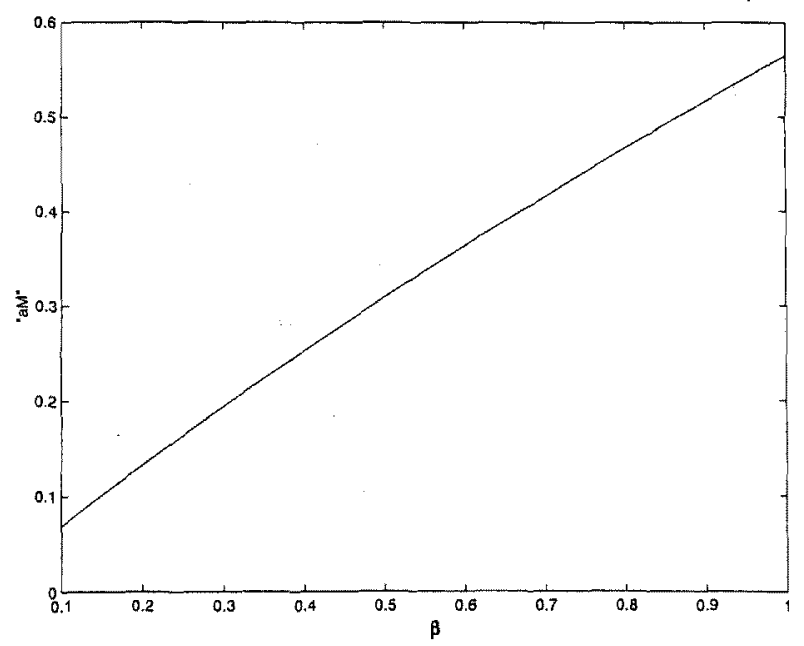

Fig.11. "aM" vs. $\beta$.

\section{Experimontal Results:}

For experiments an IGBT based converter prototype is fabricated. Rather than designing a converter assuming operating frequency and $\beta$, and then calculating the inductances and capacitance magnitudes, experiments are conducted in the laboratory for different available inductances of $306 \mu \mathrm{H}, 240 \mu \mathrm{H}, 426 \mu \mathrm{H}$ and capacitor of 0.2 $\mu \mathrm{F}$. Two different cases, one for $\gamma<1$ (i.e. $\mathrm{L}_{2}<\mathrm{L}_{1}$ ) and the other for $\gamma>1$ (i.e. $\mathrm{L}_{2}>\mathrm{L}_{1}$ ) are considered. For both the cases output voltage is decided to be kept constant at 24 volts. For the first case with $\mathrm{L}_{1}=306 \mu \mathrm{H}, \mathrm{L}_{2}=240 \mu \mathrm{H}$ and $\mathrm{C}_{1}=0.2$ $\mu \mathrm{F}, \gamma$ is found to be 0.78 . The resonant frequency at no-load $\left(f_{0}\right)$ being $20.3 \mathrm{kHz}$, operating frequency (f) is calculated to be $30.7 \mathrm{kHz}$ and assuming IGBT drop of 2.5 volts and diode drop of 2 volts, the corresponding $E_{\mathrm{IN}}$ is calculated to be 40.7 volts. Experimental results are shown in Fig.12. Initially, to find the operating frequency (i.e. the frequency at which resonance occurs under full-load condition), load current is adjusted to $2 \mathrm{~A}$ at $\mathrm{E}_{O}=24$ volts. Frequency is adjusted for resonance to occur and found to be $29.5 \mathrm{kHz}$, which is close to the calculated magnitude $(30.7 \mathrm{kHz})$. The input voltage is found to be 41 volts (instead of 40.7 volts). Also it has been found that keeping the $\mathrm{E}_{\mathrm{IN}}$ constant, lowering of load from full load (2A)(Fig.12a) to half load (1A)(Fig.12b) requires a frequency increment of $1.6 \mathrm{kHz}$ and from full load to $25 \% \operatorname{load}(0.5 \mathrm{~A})$ (Fig.12c) needs a frequency increment of $2.4 \mathrm{kHz}$. Although ideally frequency should remain same with the change in load, but in practice it is experienced that a slight increment in frequency is required. The change in frequency increases with the variation in load. However as the corresponding current through the converter devices also decreases with the increase in frequency and a good amount of output voltage controllability is achieved by frequency variation, so from the point of view of device loss and safety, this seems not a big problem. Fig.12 shows experimental waveforms for different load conditions.

For the second case $L_{1}=306 \mu H, L_{2}=426 \mu H$ and $\mathrm{C}_{1}=0.2 \mu \mathrm{F}$ are selected. These give a $\gamma$ of 1.39 . The no-load resonant frequency $f_{0}$ remains same at $20.3 \mathrm{kHz}$, the operating frequency becomes $26.6 \mathrm{kHz}$ and again considering IGBT drop of 2.5 volts and diode drop of 2 volts, the required $\mathrm{E}_{\mathrm{IN}}$ is found to be 25.1 volts for $\mathrm{E}_{0}=24$ volts. Experimental waveforms are shown in Fig.13, which indicates $\mathrm{f}=26.4 \mathrm{kHz}$ (instead of $26.6 \mathrm{kHz}$ ) and $\mathrm{E}_{\mathrm{IN}}=26$ volts (instead of 25.1 volts). Output load is reduced from full load (2A)(Fig.13a) to $25 \%$ load $(0.5 \mathrm{~A})$ (Fig.13c) needing a frequency increment of only $1.7 \mathrm{kHz}$.

The $M$ vs. $\omega / \omega_{0}$ Characteristics have been obtained from analysis for the two cases corresponding to $\gamma=0.78$ (with $\mathrm{L}_{1}=306 \mu \mathrm{H}, \mathrm{L}_{2}=240 \mu \mathrm{H}$ and $\mathrm{C}_{1}=0.2 \mu \mathrm{F}$ ) and $\gamma=1.39$ (with $\mathrm{L}_{1}=306 \mu \mathrm{H}, \mathrm{L}_{2}=426 \mu \mathrm{H}$ and $\mathrm{C}_{1}=0.2 \mu \mathrm{F}$ ) as discussed above and shown in Fig.14 and Fig.15 respectively. Experiments have been conducted to verify the analytical results. Experimental points have been shown in Fig.14 and Fig.15. A fairly good agreement between analytical and experimental result has been obtained.

It is important to note that at absolute no-load, the output filter capacitor is charged corresponding to the peak magnitude of the voltage across $C_{1}$ rather than by the average of the current flowing through $\mathrm{L}_{2}$ as in the loaded condition, thus increasing the voltage gain and requiring a wider increase in frequency as shown in Fig.12d and 13d. 
L-C-L Converter for Voltage Regulator Type Applications

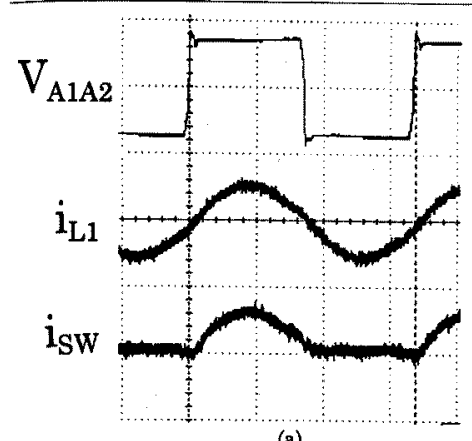

For Full Load

Load Current $=2 A$, Frequency

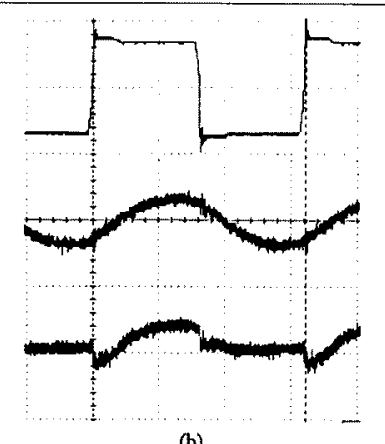

(b)

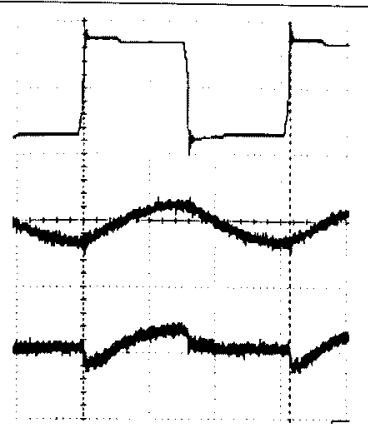

(c)

For Quarter Load

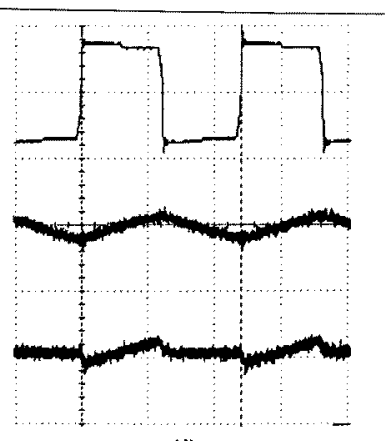

(d)

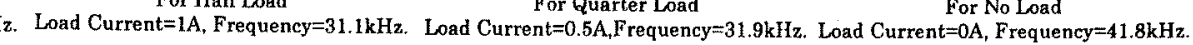

Fig.12

Experimental Waveforms for $\gamma<1$

(Volt Scale=50 Volts/div. Amp Scale=5A/div. Time Scale=10 $\mu$ s/div.)

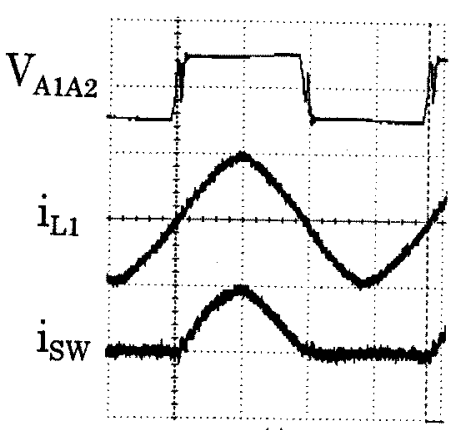

(a)

For Full Load
For Half Load

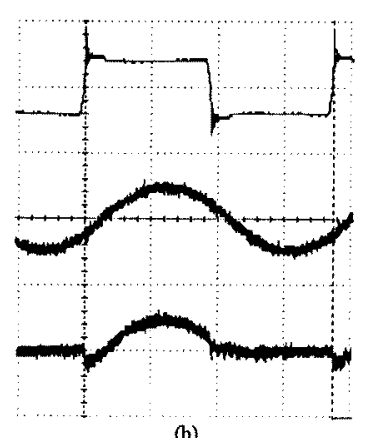

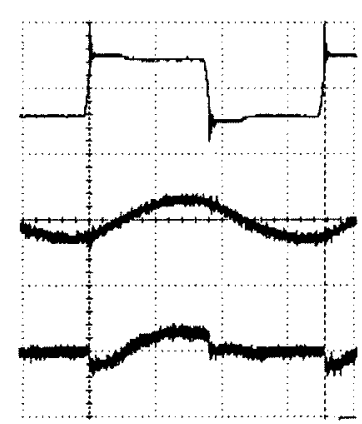

(c)

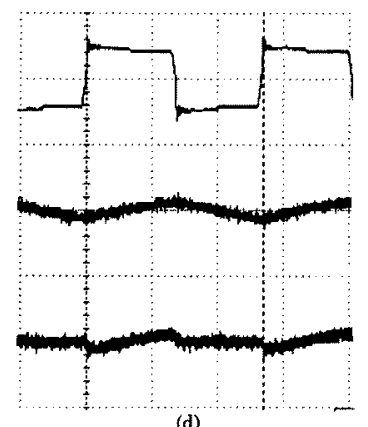

(d)

For No Load

For Quarter Load

Fig. 13

Experimental Waveforms for $\gamma>1$

(Volt Scale $=50$ Volts $/$ div. Amp Scale=5A/div. Time Scale $=10 \mu \mathrm{s} / \mathrm{div}$.)

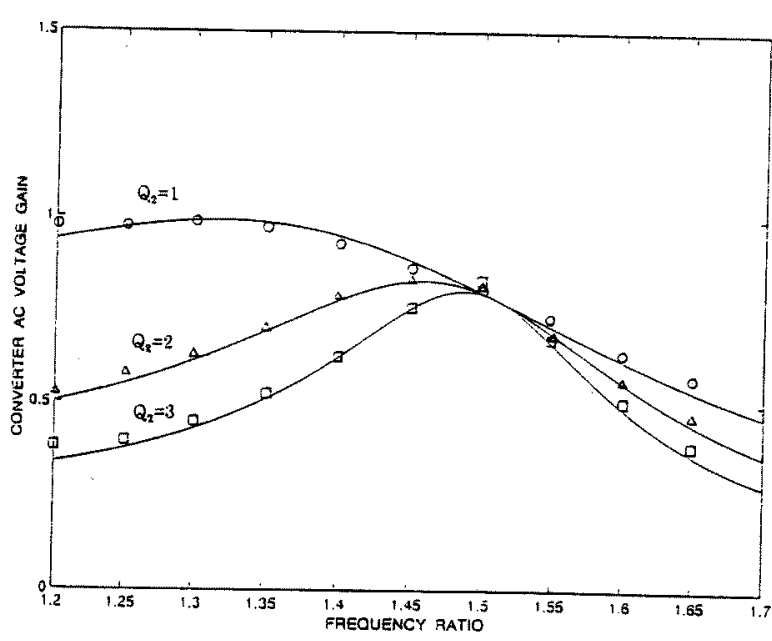

Fig.14. M vs. $\omega / \omega_{0}$ Characteristic for $\gamma=0.78$

( $\mathrm{L}_{1}=306 \mu \mathrm{H}, \quad \mathrm{L}_{2}=240 \mu \mathrm{H}, \quad \mathrm{C}_{1}=0.2 \mu \mathrm{F}$ )

\section{Conclusions:}

Analytical Data, $\mathrm{O} \Delta \mathrm{\square}$ Experimental Points

This paper has presented the design guide-line of an L-C-L converter for voltage regulator type applications. Only lagging power factor mode is considered because it does not require any device snubber. The performance and analysis show the existence of a unique $\gamma\left(=\mathrm{L}_{2} / \mathrm{L}_{1}\right)$ for constant frequency operation. Design procedure to improve part-load efficiency is also discussed. It has been shown that by a judicious choice of $\beta$ and $\gamma$, a better design results.

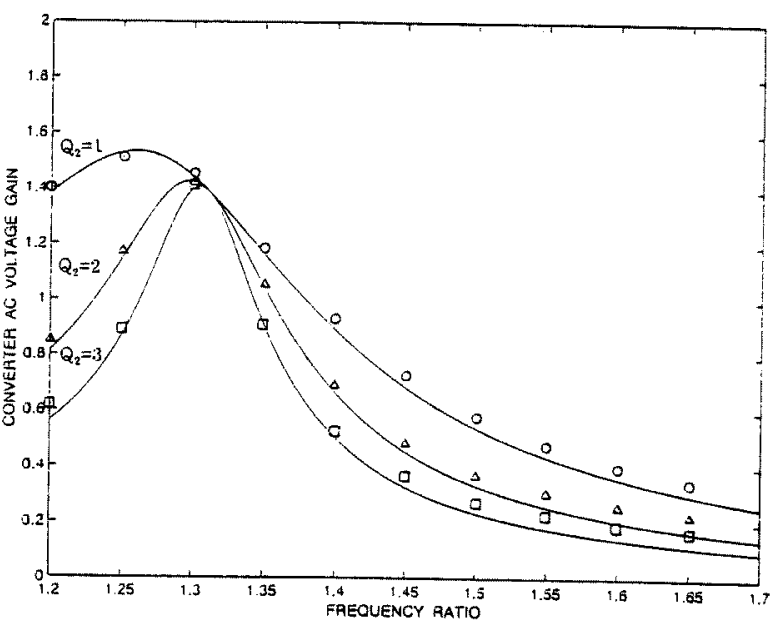

Fig.15. $\quad M$ vs. $\omega / \omega_{0}$ Characteristic for $\gamma=1.39$ $\left(\mathrm{L}_{1}=306 \mu \mathrm{H}, \quad \mathrm{L}_{2}=426 \mu \mathrm{H}, \quad \mathrm{C}_{1}=0.2 \mu \mathrm{F}\right.$ ) Analytical Data, $\mathrm{O} \Delta$ घExperimental Points

The analysis also shows the way to find trade-off solutions for conflicting design requirements. The proposed design technique is proved by experiments. The results from experiments are found to be sufficiently close to that calculated from the analysis, the difference being due to the assumptions of ideal device and components. The results will definitely help in designing an L-C-L converter with better performance in case of voltage regulator type applications.

電学論D, 119 巻 6 号, 平成 11 年 
(Manuscript received Aug. 24, 1998, revised Dec. 28, 1998)

\section{Aeierences:}

[1] M.H.Rashid, "Power Electronics" Englewood Cliffs, NJ: Prentice Hall, 1988.

[2] N.Mohan, T.M.Undeland and W.P.Robbins, "Power Electronics: Converters, Applications and Design", John Wiley \& Sons, 1989.

[3] M.K.Kazimierczuk and D.Czarkowski, "Resonant Power Converters", John Wiley, 1995.

[4] V.T.Ranganathan, P.D.Ziogas and V.R.Stefanovic, "A regulated dc-dc voltage source converter using a high frequency link," IEEE Trans. on Ind. Appl., Vol.IA-18, pp.279-287, No.3, 1982.

[5] R.L.Steigerwald, "High-frequency resonant transistor dc-dc converter," IEEE Trans on Ind. Ecs., Vol.IE-31, pp.181-191, 1984.

[6] R.Oruganti and F.C.Lee, "Resonant power processors, Part I-State plane analysis," IEEE Trans Ind. on Appl. Vol.IA-21, pp.1453-1960, 1985.

[7] R.L.Steigerwald, "A comparison of half-bridge resonant converter topologies," IEEE Trans. on Pwr. Ecs., Vol.PE-3, pp.174-182, 1988.

[8] H.Seidel, "A high power factor tuned class D converter",PESC 88 Record, Kyoto, Japan, pp.10381042.

[9] A.K.S.Bhat and M.M.Swamy, "Analysis of parallel resonant converter operating above resonance" IEEE Trans. on Aero. \& Elc. Sys., Vol.AES-25, pp.449-458, 1989.

[10] R.P.Severns, "Topologies of three-element resonant converters", IEEE Trans. on Pwr. Ecs., Vol.PE-7, pp.89-98, 1992

[11] W.J.Gu and K.Harada, "A circuit model for the class E resonant DC-DC converter regulated at a fixed switching frequency", IEEE Trans. on Pwr. Ecs, Vol.PE-7, pp.99-110, 1992.

[12] K.Harada, A.Katsuki, M.Fujiwara, H.Nakajima and H.Matsushita, "Resonant converter controlled by variable capacitance devices", IEEE Trans. on Pwr. Ecs. Vol.8, pp.404-410, 1993.

[13] A.K.S.Bhat, "Analysis and design of a series-parallel resonant converter," IEEE Trans. on Pwr. Ecs., Vol.PE-8, pp.1-11, 1993.

[14] I.Batarseh, "Resonant converter topologies with three and four energy storage elements", IEEE Trans. on Pwr. Ecs. Vol.PE-9, pp.64-73, 1994.

[15] A.K.S.Bhat, "Analysis and design of a modified series resonant converter", IEEE Trans. on Pwr Ees., vol.PE4, pp.423-430, 1993.

[16] G.S.N.Raju and S.Doradla, "An L-C-L converter with PWM control-analysis, simulation and implementation", IEEE Trans. on Pwr. Ecs. Vol.PE-10, pp.164-173, 1995.

[17] J.H.Cheng and A.F.Witulski, "Analytic solution for LLCC parallel resonant converter simplify use of twoand three-element converters", IEEE Trans. on Pwr. Ecs. Vol.PE-13, pp.235-243, 1998.

\section{Acknowledgement:}

One of the authors, Chandan Chakraborty, acknowledges Japanese Government with gratitude for the award of Monbusho Scholarship.

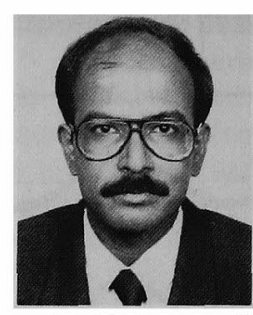

Chandan Chakraborty was born on August 17, 1965 in Calcutta, India He received B.E.E(Hons.) and M.E.E degree from Jadavpur University, Calcutta in 1987 and 1989 respectively and $\mathrm{Ph} . \mathrm{D}$ from Indian Institute of Technology, Kharagpur in 1996. Since 1993 , he is a lecturer in Electrical Engineering Department at the Jadavpur University. Presently he is a monbusho researcher at the Mie University. His areas of interests are Power Electronics, Electric Drives, Magnetics and Renewable Energy Systems.

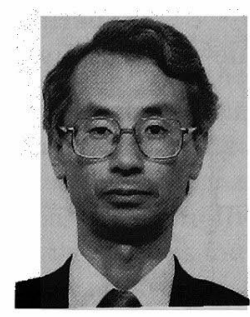

Muneaki Ishida was born in Aichi, Japan on April 12, 1952. He received the B.S., M.S., and Ph.D degrees from Nagoya University in 1975, and 1980 respectively, all in Electrical and Electronic Engineering. $\mathrm{He}$ was with Nagoya University as a Research Associate in the Department of Electrical Engineering from 1980 to 1987. Since 1987, he has been with Mie University, initially as an Associate professor and from October, 1996 as a Professor. He is engaged in research on static power converters, AC motor drive systems and development of new type motors using piezo-electric devices.

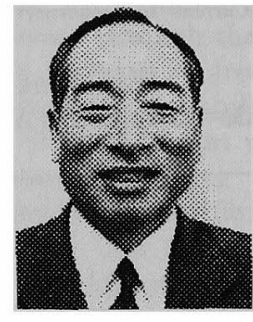

Takamasa Hori was born in Toyama, Japan in October, 1938. He received the B.S. degree in 1961 and the $\mathrm{Ph} . \mathrm{D}$ degree in 1970 from Osaka University both in Electrical Engineering. From 1961 to 1986 , he was with the Hitachi Research Laboratory of Hitachi Ltd. engaging In engineering research and development on Power Electronics. Since 1987, he has been a professor of Mie University. His research interests include resonant converters, servo motor control, inverter drive system and small actuator for robotics and information equipment.

Dr. Hori has received two prize paper awards and is a Fellow of IEEE and SICE Japan. He is also an AdCom member since 1984 in IEEE/IES. 